\title{
The Effect of Cleft Palate Repair on Contractile Properties of Single Permeabilized Muscle Fibers From Congenitally Cleft Goat Palates
}

Michael C. Hanes, BS $\ddagger$, Jeffrey Weinzweig, MD§, Kip E. Panter, PhD\|, W. Thomas McClellan, MD§, Stefanie A. Caterson, MD§, Steven R. Buchman, MD ${ }^{\star}$, John A. Faulkner, PhD $¥$, Deborah Yu, MD ${ }^{\star}$, Paul S. Cederna, MD $^{\star}, \mp$, and Lisa M. Larkin, PhD ${ }^{\dagger}, \neq$

*Section of Plastic Surgery, University of Michigan, Ann Arbor, MI

${ }^{\dagger}$ Geriatric Medicine, University of Michigan, Ann Arbor, MI

\#Institute of Gerontology, University of Michigan, Ann Arbor, MI

$\S$ Department of Plastic Surgery, Lahey Clinic, Burlington, MA

"Poisonous Plant Research Laboratory, USDA Agricultural Research Service, Logan, UT.

\begin{abstract}
Inherent differences in the levator veli palatini (LVP) muscle of cleft palates before palatoplasty may play a role in persistent postrepair velopharyngeal insufficiency (VPI). Contractile properties of LVP muscle fibers were analyzed from young (2-month) normal (YNP), young congenitally cleft (YCP) and again on the same YCP subjects 6 months after palatoplasty, mature repaired palate (MRP). The cross-sectional area and rate of force development $\left(\mathrm{k}_{\mathrm{tr}}\right)$ were measured. Specific force $\left(\mathrm{sF}_{0}\right)$ and normalized power $\left(\mathrm{nP}_{\max }\right)$ were calculated. Using $\mathrm{k}_{\mathrm{tr}}$ to determine fiber type composition, $\mathrm{YNP}$ was $44 \%$ type 1 and $56 \%$ type 2, while YCP was $100 \%$ type 2 . Two MRP subjects shifted to $100 \%$ type $1 ; 1$ demonstrated increased resistance to fatigue. No differences in $\mathrm{sF}_{0}$ were observed. $\mathrm{nP}_{\max }$ increased with presence of type 2 fibers. The persistent state of type 2 fibers following palatoplasty leads to increased fatigue in the LVP of MRP subjects and may cause VPI symptoms.
\end{abstract}

\section{Keywords}

cleft palate; palatoplasty; contractile properties; single permeabilized muscle fibers

Approximately 6800 children in the United States are born with orofacial clefts each year, making it the most prevalent birth defect in the United States. Residual velopharyngeal insufficiency (VPI) following palatoplasty remains a problem for $15 \%-25 \%$ of these patients and requires secondary surgery to correct. ${ }^{1-5}$ The reasons for this high incidence of VPI are not well understood. Some attribute the development of VPI to surgical technique and therefore seek new procedures to improve surgical outcomes. However, evidence suggests that inherent differences exist in the levator veli palatini muscle (LVP) of some cleft palate patients that make them susceptible to VPI following cleft repair.

\section{Copyright $@ 2008$ by Lippincott Williams \& Wilkins}

Reprints: Lisa M. Larkin, Molecular and Integrative Physiology, BSRB, Room 2025, 109 Zina Pitcher Place, University of Michigan, Ann Arbor, MI 48109-2200. E-mail: 1larkin@umich.edu. 
While palatoplasty techniques have improved in recent years, VPI remains a common problem regardless of the surgical technique. Several studies have found no difference in speech outcomes both among procedures and surgeons. ${ }^{2,6-9}$ Several studies have found improved speech outcomes using new techniques, yet in all cases described some level of residual speech impairment remains in a subpopulation of these patients. For example, Henkel et al ${ }^{10}$ reported improved speech outcomes using the wave-line technique compared with the intravelar veloplasty. However, this study had a small number of subjects, and significant speech deficiencies were still found in the wave-line technique. Additionally, Gunther et al ${ }^{11}$ compared the Furlow double reversing Z-plasty to the intravelar veloplasty and reported improved speech results with the Furlow technique. However, the difference was not statistically significant, and the authors emphasized the need for further investigation. Therefore, the high incidence of VPI in a subpopulation of patients points to an alternate explanation: the presence of an inherent difference in the palatal musculature prior to surgical intervention affects its ability to attain full function following surgical repair.

Several studies have identified characteristics of the cleft palate musculature that may explain the variability in palatoplasty outcomes. Lindman et al ${ }^{12}$ observed a variation in fiber size with an overall smaller mean fiber diameter, an increase in the proportion of type 2 (fast) fibers and an increase in the amount of fast myosin heavy chain composition in the LVP muscles from infant cleft palates compared with those of normal adults. Cohen et $\mathrm{al}^{13}$ observed disorganization in fiber orientation in LVP muscles of cleft palates. Schendel et $\mathrm{al}^{14}$ found that isolated human cleft palate muscle contained a mixture of type 1 (slow) and type 2 fiber. Weinzweig et a 15 observed degeneration of myofibrils and Z-bands in the goat congenital cleft palate model, which was the animal model for this study.

Previous studies in our laboratory found that LVP muscle fibers in mature normal goat palates (MNP) were exclusively type 1 and those from the mature congenital-cleft palate goat model (MCP) were predominantly type 2 . In addition, these type 2 muscle fibers from the MCP were more prone to lengthening-induced injuries and had less resistance to fatigue than the type 1 fibers of the normal goat palates. ${ }^{16,17}$ These studies report a significant difference between the fiber type composition of the LVP of the MNP and MCP groups. Therefore, the increased percentage of type 2 muscle fibers in the cleft palate LVP make the muscle more fatigable and may indicate an etiology of VPI symptoms.

Force measurements on permeabilized muscle fibers have been shown to represent whole muscle contractile properties. Therefore, this technique allowed us to evaluate the functional properties of the LVP muscle without compromising the muscle.

Therefore, the present study used single permeabilized muscle fibers to study the effects of palatoplasty on the contractile properties of the LVP. The rate of maximum isometric force production, specific force $\left(\mathrm{sF}_{0}\right)$, normalized maximum power $\left(\mathrm{nP}_{\max }\right)$, and fatigability in response to a series of isometric contractions was measured. Understanding the effect of cleft repair on palatal musculature may help reveal susceptibility or other problems associated with VPI, which may produce effective solutions.

\section{METHODS AND MATERIALS}

\section{Congenital Cleft Palate Model}

This study used animals from 3 groups of the congenital cleft palate goat model developed by Weinzweig et al: young, 2-month-old goats with normal palates (YNP); young, 2-month-old congenitally cleft goats prior to palatoplasty (YCP); and the same congenitally cleft goats 6 months following palatoplasty (MRP). ${ }^{18}$ These data were also compared with previously described data collected in our laboratory on mature goats with normal palates (MNP) and cleft 
palates (MCP). ${ }^{17}$ Cleft palates were induced, as previously described, by gavaging pregnant Spanish goats with a Nicotiana glauca plant slurry, containing anabasine, a natural teratogen, twice daily from days 32 to 41 of gestation (term $=145$ days). ${ }^{17-19}$ In the cleft palate groups, small LVP muscle biopsies were obtained during the cleft repair procedure, and again 6 months following repair. A modified von Langen-beck technique, utilizing lateral relaxing incisions to produce a tension-free midline closure, was used to repair the palates. ${ }^{20}$

\section{LVP Muscle Bundle Harvest and Preparation of Single Permeabilized Fibers}

LVP muscle biopsies were harvested, processed, and single permeabilized fibers were extracted as previously described from the postero-medial aspect of the soft palate. ${ }^{17}$

\section{Single Fiber Contractile Properties}

Each single fiber was then transferred to a $15^{\circ} \mathrm{C}$ chamber and contractile properties were determined as previously described. ${ }^{17}$ Briefly, one end of the fiber was secured to a force transducer and the other end was secured to the lever arm of a servomotor. Sarcomere length was set at $2.5 \mu \mathrm{m}$, fiber length $\left(\mathrm{L}_{\mathrm{o}}\right)$ was measured using a calibrated micrometer, and fiber diameters were estimated at $\mathrm{L}_{\mathrm{o}}$ using high-magnification digital images obtained from top and side views of the fiber. ${ }^{17}$

Each fiber was then transferred to a chamber containing a low- $\left[\mathrm{Ca}^{2+}\right]$ preactivation solution (pH 7.1). Passive tension was measured, and then each fiber was moved into a chamber containing activation solution. The fiber was allowed to contract until it reached its maximum tetanic isometric force production. Each fiber was then returned to relaxation solution and stretched to $\mathrm{L}_{0}+10 \%$. It was then reactivated and cycled through a series of 16 shortening ramps at decreasing velocities. The size of the step ranged from $3 \%-5 \%$ of $\mathrm{L}_{\mathrm{o}}$. The velocity of each ramp was plotted versus the force $\left(\mathrm{F}_{0}\right)$ regenerated during each shortening ramp. The peak of the curve was recorded as the maximum power generating capacity $\left(\mathrm{P}_{\max }\right) \cdot \mathrm{P}_{\max }$ was then divided by the fiber volume $\left(\mathrm{L}_{0} \times \mathrm{CSA}\right)$ to obtain $\mathrm{nP}_{\max }$. Fiber fatigue during a 10-minute isometric contraction was determined using a Brenner cycle to ensure the fatigue was not caused by the inability for permeabilized fibers to keep their sarcomeres aligned after prolonged activation. ${ }^{21}$ The percentage of force maintained by each fiber at the end of the protocol was calculated and used as a measure of fatigability. Lower percentages represent greater fatigability.

\section{Determination of Fiber Type}

Fiber type was assigned to each fiber by determining their rate constants of tension redevelopment $\left(\mathrm{k}_{\mathrm{tr}}\right)$ following 1 cycle of activation. The $\mathrm{k}_{\mathrm{tr}}$ can be used as an indirect measure of fiber type ${ }^{17,22}$ because the $\mathrm{k}_{\mathrm{tr}}$ is indicative of the kinetics of attachment and detachment reactions of cross-bridges. ${ }^{23}$

\section{Statistics}

Values are presented as means \pm standard error (SE). Statistical analysis was performed by using Jump In 5.1 (SAS Institute Inc, Cary, NC). A 1-way analysis of variance (ANOVA) was conducted to compare the differences between normal and cleft palate LVP muscle when the variance was not evenly distributed; the nonparametric Mann-Whitney analysis was conducted. Differences were considered significant at $P<0.05$. 


\section{RESULTS}

\section{Fiber Type}

The percentage of type 1 and type 2 fibers from the LVP muscle of YCP ( $n=28$ fibers), YNP ( $\mathrm{n}=18$ fibers), MNP ( $\mathrm{n}=22$ fibers), MCP ( $\mathrm{n}=21$ fibers), and MRP ( $\mathrm{n}=30$ fibers) subjects is presented in Figure 1. Data for the MRP group were separated by subject to properly represent the findings because variations in fiber type composition were found among subjects in this group. Fiber-type composition was measured as a percentage of type 1 and type 2 muscle fibers within a random sampling of muscle fibers extracted from each LVP sample. Sixty-five percent of the muscle fibers from the YNP group were type 2 fibers, and the remaining $35 \%$ were type 1 fibers. In contrast, the muscle fibers from the YCP group were 100\% type 2 . The muscle fibers obtained from 2 of the MRP subjects were 100\% type 1, and those from the third MRP subject remained $100 \%$ type 2 .

Cross-Sectional Area-The only significant difference in muscle fiber CSA between groups was due to the age of the subjects $(P=0.0001$; Fig. 2$)$. Average CSA increased with age of the subject. The CSAs of permeabilized muscle fibers were as follows: YNP (1286 \pm $\left.85 \mu \mathrm{m}^{2}\right)$, YCP $\left(1031 \pm 77 \mu \mathrm{m}^{2}\right)$, and MRP $\left(1780 \pm 74 \mu \mathrm{m}^{2}\right)$. All of the values for CSA are $20 \%-50 \%$ larger than the values for intact fibers since permeabilized fibers become swollen due to their storage in the glycerol solution. ${ }^{24,25}$

Contractile Properties-YNP muscle fibers produced significantly less $\mathrm{sF}_{0}(87 \pm 3 \mathrm{kN} /$ $\left.\mathrm{m}^{2}\right)$ than YCP $\left(107 \pm 3 \mathrm{kN} / \mathrm{m}^{2}\right)$ and MRP $\left(104 \pm 3 \mathrm{kN} / \mathrm{m}^{2}\right)$ fibers $(P<0.0001 ; P=0.0002$; Fig. 3). No differences in $\mathrm{sF}_{0}$ were found between MRP and YCP $(P=0.4746)$. The average $\mathrm{nP}_{\max }$ of YNP $(4.7 \pm 0.8 \mathrm{~W} / \mathrm{l})$ and MRP $(3.85 \pm 1.0 \mathrm{~W} / \mathrm{l})$ was significantly less than that of $\mathrm{YCP}(7.9 \pm 0.5 \mathrm{~W} / \mathrm{l} ; P=0.0001)$. The average $\mathrm{nP}_{\max }$ of type 1 muscle fibers from YNP $(2.3$ $\pm 0.2 \mathrm{~W} / \mathrm{l})$ was significantly greater than that of type 1 muscle fibers from MRP $(1.3 \pm 0.1 \mathrm{~W} /$ $1 ; P=0.0008)$. Type 2 muscle fibers had greater $\mathrm{nP}_{\max }$ values than type 1 muscle fibers within and between all groups (Fig. 4; $P=0.0001)$. One out of the 3 MRP subjects was $(96 \pm 4 \%$ ) more resistant to fatigue than the other $2 \mathrm{MRP}$ subjects $(86 \pm 3 \% ; 86 \pm 2 \% ; P=0.0078)$ and also when compared with the MCP group $(80 \pm 2 \% ; P<0.0001 ;$ Fig. 5). This MRP subject's resistance to fatigue was significantly greater than that of the YCP group $(88 \pm 3 \% ; P=0.0433)$ and equivalent to that of the MNP group $(94.5 \pm 0.8 \%)$. The YCP subject that corresponds to the MRP subject with an increased ability to resist fatigue also shows a slight, yet not significant, increase in its ability to resist fatigue compared with the other 2 YCP subjects $(P$ $=0.1426 ; P=0.7646$; Fig. 6 ).

\section{DISCUSSION}

The present study examined the contractile properties of single permeabilized muscle fibers obtained from the LVP muscle of 2-month-old congenitally cleft goat palates, age-matched goats with normal palates, and the congenitally cleft goats 6 months following cleft repair. A previous study in our laboratory found the LVP from the MNP group had predominantly type 1 , slow, fatigue-resistant muscle fibers, and that from the MCP group had predominantly type 2 , highly fatigable muscle fibers. ${ }^{17}$ Therefore, the finding of $65 \%$ type 2 muscle fibers in the YNP group and 100\% type 2 in the YCP group suggests that as both groups mature, a percentage of the type 2 LVP muscle fibers experiences a fiber type shift to type 1. Previous studies have shown postdevelopmental shifts in fiber type from slow to fast in response to a lack of tension development or in response to varied loads applied to the muscle. ${ }^{26,27}$ As LVP matures, the muscles experience increased tension for extended periods of time. Type 1 muscle fibers are less resistant to fatigue and therefore are better suited for this type of tension development. ${ }^{28}$ 
Therefore, the developmental fast to slow fiber type shift of the LVP in normal palates occurs to provide the most efficient fiber type (type 1) for the muscle's proper function.

Two thirds of our cleft palate subjects were able to undergo this fiber type shift 6 months following palatoplasty. Many possible explanations exist for the third subject's inability to undergo what seems to be a developmental fiber type shift. Lack of innervation from the greater palatine nerve could be the cause for the predominance of type 2 muscle fibers in the MCP subjects. This theory agrees with other studies, which have shown that during normal muscle development, a muscle fiber begins as a type 2 fiber and either remains type 2 or shifts to a type 1 fiber following complete innervation. ${ }^{29}$ Subsequent studies are under way to determine the level of innervation from the greater palatine nerve in each subject. Improper realignment of the LVP could inhibit proper tension development and subsequently fiber type shifting. In addition, hyperlengthening of the muscle during surgery poses a greater risk of injury in type 2 muscle fibers during surgery or following surgery once the subjects begin using the LVP.

${ }^{16}$ Hyperlengthening of the muscle could be due to a wider cleft, among other variables.

Our data are also consistent with studies in humans that have shown an increase in type 2 fibers in LVP of cleft palates compared with normal palates. ${ }^{12,14}$ Lindman et al ${ }^{12}$ characterized the cleft palate musculature of human infants (age range, 18-21 months) and compared them to the LVP obtained from 5 adults (age range, 46-75 years). They observed 36.9\% type 1 and $63.1 \%$ type 2 in the infant cleft palate LVP versus $74.9 \%$ type 1 and $25.1 \%$ type 2 in the normal adult LVP. Schendel et al ${ }^{14}$ obtained muscle biopsies from human cleft palate patients (age range, 2-10 months) and also found a mixed fiber type composition (56.7\% type 1 and $43.3 \%$ type 2). These results confirm that the congenital cleft palate goat model is appropriate to study the affects of LVP development following palatoplasty for comparison in humans because fiber type composition of the various groups is very similar.

Force measurements on permeabilized muscle fibers have been shown to represent whole muscle contractile properties. Trappe et $\mathrm{a}^{30}$ found that differences between the contractile properties of single permeabilized muscle fibers and whole muscle were due to variations in the CSA of each subject's whole muscle. Therefore, this technique allowed us to evaluate the functional properties of the LVP muscle without compromising the muscle. Ideally, this technique could be applied in humans as a preoperative test to determine a patient's susceptibility to postoperative VPI.

Significant differences in $\mathrm{sF}_{0}$ and $\mathrm{nP}_{\max }$ production among muscle fibers in this study were primarily due to differences in fiber type. $\mathrm{SF}_{0}$ tends to be reduced in slow muscle fibers, which constituted $100 \%$ of the muscle fiber type composition of the YNP group. The $\mathrm{nP}_{\max }$ of type 2 muscle fibers from all subjects was significantly greater than that of the type 1 fibers. This is consistent with Widrick et al, ${ }^{31}$ who observed type 2 fibers producing 5 to 10 times more normalized power than type 1 fibers. The only difference found between groups when comparing equivalent fiber types was between the average $\mathrm{nP}_{\max }$ of type 1 muscle fibers from YNP $(2.3 \pm 0.2 \mathrm{~W} / 1)$, which was significantly greater, and MRP $(1.3 \pm 0.1 \mathrm{~W} / 1 ; P=0.0008)$. This may indicate continued decrease in function even in those LVP muscle fibers that convert to their proper fiber type following palatoplasty. When combining fiber types and comparing $\mathrm{nP}_{\max }$ values, those groups with the most type 2 fibers had the greatest average $\mathrm{nP}_{\max }$. While this may seem beneficial, this functional characteristic is due to the increased percentage of type 2 muscle fibers. The type 2 muscle fibers, although more powerful, fatigue much more rapidly than type 1 muscle fibers. Therefore, in terms of their utilization in the soft palate, the type 2 , highly fatigable muscle fibers are detrimental.

Each group's or subject's ability to resist fatigue nearly always correlated with their muscle fiber type composition. Those subjects or groups with a higher percentage of type 2 muscle 
fibers tended to have a decreased ability to resist fatigue. However, subject $\mathrm{MRP}_{2}$, which had $100 \%$ type 2 muscle fibers, was observed to have an ability to resist fatigue comparable to that of other subjects or groups with a high percentage of type 2 muscle fibers. MRP 1 's ability to resist fatigue was equivalent to that of the MNP group (95\%). This suggests that following palatoplasty, this subject was able to undergo a complete type 2 to 1 fiber type shift that allowed the muscle to function like a normal LVP. This was also evident in the decreased $\mathrm{nP}_{\max }$ observed in the type 1 MRP muscle fibers compared with the type 1 YNP muscle fibers. This suggests that an additional intrinsic factor in $\mathrm{MRP}_{2}$ 's LVP muscle existed that caused the muscle to fatigue quickly, such as a defect in the cross-bridge cycling or sarcomere alignment. In addition, it is interesting to note that $\mathrm{YCP}_{1}$, the subject that corresponds to $\mathrm{MCP}_{1}$ at 2 months of age and prior to palatoplasty, showed a slight increase in its ability to resist fatigue compared with the other 2 YCP subjects (Fig. 6). The $\mathrm{MCP}_{1}$ subject also had the largest increase in its ability to resist fatigue following repair, when each MCP subject was compared with the respective YCP subject. This suggests that the fatigue properties of LVP muscle prior to palatoplasty indicate the subject's chances and level of improvement following cleft repair. With this in mind, special precautions can be taken or procedures performed on cleft palate patients whose LVP single permeabilized muscle fibers, prior to surgery, show a similar resistance to fatigue compared with those of previously documented cleft palate patients who suffered from post-operative VPI.

Palatoplasty allows the LVP muscle of a segment of the cleft palate population to develop normally and complete the developmental type 2 to type 1 fiber-type shift. Subsequent studies are needed to establish the presence of VPI, or a similar level of resonance insufficiency, in the congenital cleft palate model. In addition, a method to identify those LVP muscles that are likely to remain underdeveloped or a technique to ensure that their natural course of development is allowed to occur needs to be designed to diminish the incidence of postsurgical VPI.

\section{Acknowledgment}

The single muscle fiber preparation and testing was supported by the Nathan Shock Center of Excellence in Basic Biology of Aging grant P30 AG 13283. D. Yu was supported by the NIH Training Grant in Trauma, Burn, and Wound Healing Research grant T32 GM008616-06A1, respectively

\section{References}

1. Becker DB, Grames LM, Pilgram T, et al. The effect of timing of surgery for velopharyngeal dysfunction on speech. J Craniofac Surg 2004;15:804-809. [PubMed: 15346022]

2. Bicknell S, McFadden LR, Curran JB. Frequency of pharyngoplasty after primary repair of cleft palate. J Can Dent Assoc 2002;68:688-692. [PubMed: 12513937]

3. Deren OM, Ayhan A, Tuncel M, et al. The correction of velopharyngeal insufficiency by Furlow palatoplasty in patients older than 3 years undergoing Veau-Wardill-Kilner palatoplasty: a prospective clinical study. Plast Reconstr Surg 2005;116:85-93. [PubMed: 15988251]

4. Inman DS, Thomas P, Hodgkinson PD, et al. Oro-nasal fistula development and velopharyngeal insufficiency following primary cleft palate surgery: an audit of 148 children born between 1985 and 1997. Br J Plast Surg 2005;58:1051-1054. [PubMed: 16084930]

5. Timmons MJ, Wyatt RA, Murphy T. Speech after repair of isolated cleft palate and cleft lip and palate. Br J Plast Surg 2001;54:377-384. [PubMed: 11428766]

6. Dailey SA, Karnell MP, Karnell LH, et al. Comparison of resonance outcomes after pharyngeal flap and Furlow double-opposing z-plasty for surgical management of velopharyngeal incompetence. Cleft Palate Craniofac J 2006;43:38-43. [PubMed: 16405372]

7. Lin KY, Goldberg D, Williams C, et al. Long-term outcome analysis of two treatment methods for cleft palate: combined levator retropositioning and pharyngeal flap versus double-opposing Z-plasty. Cleft Palate Craniofac J 1999;36:73-78. [PubMed: 10067766] 
8. Perkins JA, Lewis CW, Gruss JS, et al. Furlow palatoplasty for management of velopharyngeal insufficiency: a prospective study of 148 consecutive patients. Plast Reconstr Surg 2005;116:72-80. [PubMed: 15988249]

9. Ysunza A, Pamplona MC. Velopharyngeal function after two different types of pharyngoplasty. Int J Pediatr Otorhinolaryngol 2006;70:1031-1037. [PubMed: 16309748]

10. Henkel KO, Dieckmann A, Dieckmann O, et al. Veloplasty using the wave-line technique versus classic intravelar veloplasty. Cleft Palate Craniofac J 2004;41:1-4. [PubMed: 14697077]

11. Gunther E, Wisser JR, Cohen MA, et al. Palatoplasty: Furlow's double reversing Z-plasty versus intravelar veloplasty. Cleft Palate Craniofac J 1998;35:546-569. [PubMed: 9832228]

12. Lindman R, Paulin G, Stål PS. Morphological characterization of the levator veli palatini muscle in children born with cleft palates. Cleft Palate Craniofac J 2001;38:438-448. [PubMed: 11522165]

13. Cohen SR, Chen LL, Burdi AR, et al. Patterns of abnormal myogenesis in human cleft palates. Cleft Palate Craniofac J 1994;31:345-350. [PubMed: 7986794]

14. Schendel SA, Cholon A, Delaire J. Histochemical analysis of cleft palate muscle. Plast Reconstr Surg 1994;94:919-923. [PubMed: 7972479]

15. Weinzweig J, Panter KE, Spangenberger A, et al. The fetal cleft palate, III: ultrastructural and functional analysis of palatal development following in utero repair of the congenital model. Plast Reconstr Surg 2002;109:2355-2362. [PubMed: 12045563]

16. Rader EP, Cederna PS, Weinzweig J, et al. Contraction-induced injury to single permeabilized muscle fibers from normal and congenitally-cleft goat palates. Cleft Palate Craniofac J 2007;44:216-222. [PubMed: 17328650]

17. Hanes MC, Weinzweig J, Panter KE, et al. The effect of cleft palate repair on contractile properties of single permeabilized muscle fibers from congenitally-cleft goat palates. Plast Reconstr Surg 2006;119:3.

18. Weinzweig J, Panter KE, Pantaloni M, et al. The fetal cleft palate: I. characterization of a congenital model. Plast Reconstr Surg 1999;103:419-428. [PubMed: 9950527]

19. Panter KE, Keeler RF. Induction of cleft palate in goats by Nicotiana glauca during a narrow gestational period and the relation to reduction in fetal movement. J Natural Toxins 1992;1:25.

20. Weinzweig J, Panter KE, Pantaloni M, et al. The fetal cleft palate: II. scarless healing after in utero repair of a congenital model. Plast Reconstr Surg 1999;104:1356-1364. [PubMed: 10513918]

21. Brenner B. Technique for stabilizing the striation pattern in maximally calcium-activated skinned rabbit psoas fibers. Biophys J 1983;41:99-102. [PubMed: 6824759]

22. Wahr PA, Rall JA. Role of calcium and cross bridges in determining rate of force development in frog muscle fibers. Am J Physiol 1997;272:C1664-C1671. [PubMed: 9176158]

23. Burton K, White H, Sleep J. Kinetics of muscle contraction and actomyosin NTP hydrolysis from rabbit using a series of metal-nucleotide substrates. J Physiol 2005;563:689-711. [PubMed: 15611022]

24. Elzinga G, Stienen GJ, Wilson MG. Isometric force production before and after chemical skinning in isolated muscle fibres of the frog Rana temporaria. J Physiol 1989;410:171-185. [PubMed: 2795477]

25. Godt RE, Maughan DW. Influence of osmotic compression on calcium activation and tension in skinned muscle fibers of the rabbit. Pflugers Arch 1981;391:334-337. [PubMed: 7312568]

26. Trappe S, Trappe T, Gallagher P, et al. Human single muscle fibre function with 84 day bed-rest and resistance exercise. J Physiol 2004;557:501-513. [PubMed: 15064323]

27. Widrick JJ, Romatowski JG, Norenberg KM, et al. Functional properties of slow and fast gastrocnemius muscle fibers after a 17-day spaceflight. J Appl Physiol 2001;90:2203-2211. [PubMed: 11356784]

28. Fitts RH. Cellular mechanisms of muscle fatigue. Physiol Rev 1994;74:49-94. [PubMed: 8295935]

29. Wigmore PM, Evans DJ. Molecular and cellular mechanisms involved in the generation of fiber diversity during myogenesis. Int Rev Cytol 2002;216:175-232. [PubMed: 12049208]

30. Trappe S, Gallagher P, Harber M, et al. Single muscle fibre contractile properties in young and old men and women. J Physiol 2003;552:47-58. [PubMed: 12837929] 
31. Widrick JJ, Trappe SW, Blaser CA, et al. Isometric force and maximal shortening velocity of single muscle fibers from elite master runners. Am J Physiol 1996;271:C666-C675. [PubMed: 8770008] 


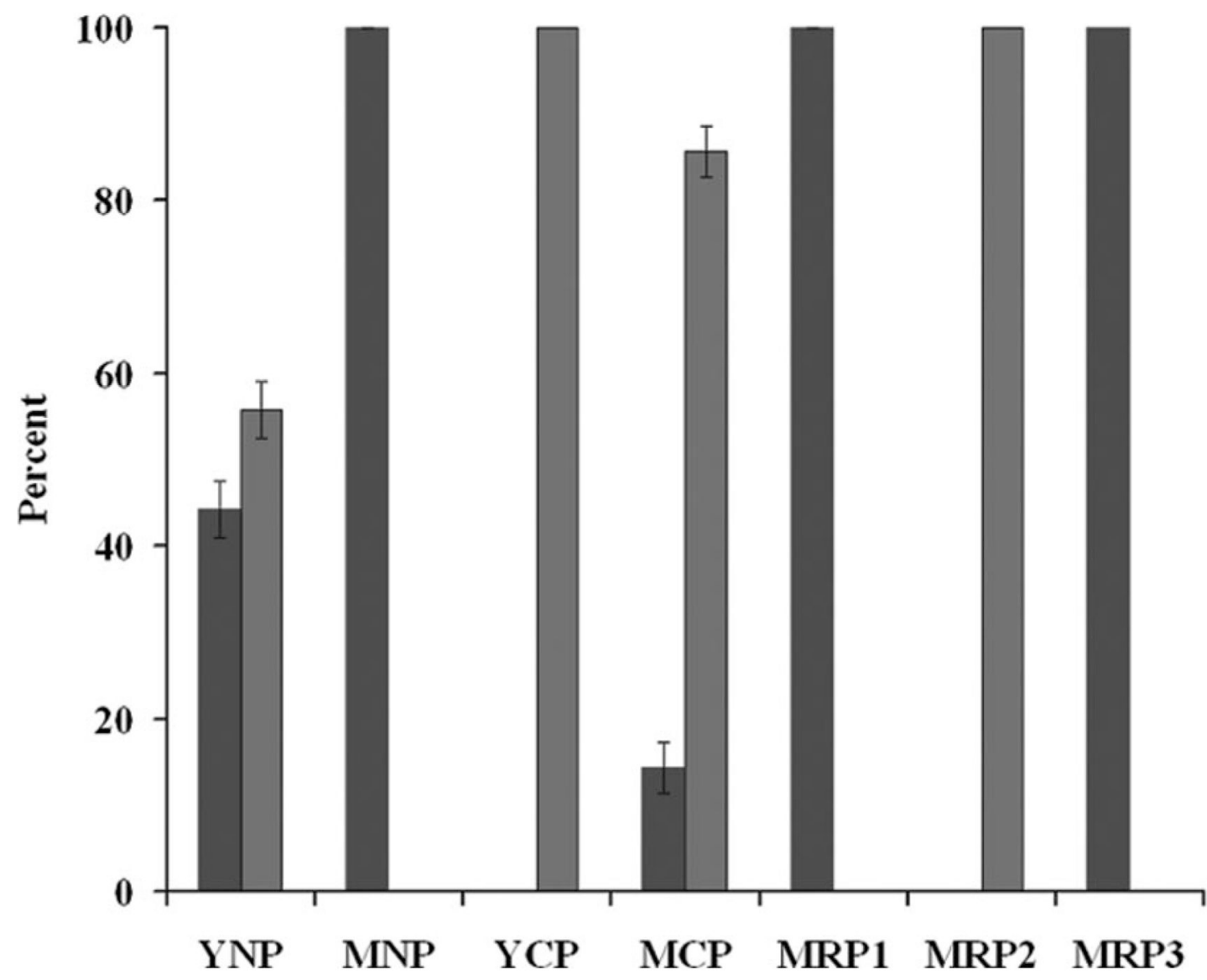

FIGURE 1.

The percentage of type 1 and type 2 muscle fibers within a random sampling of muscle fibers from each LVP sample was ascertained by determining the rate constants of tension redevelopment $\left(\mathrm{k}_{\mathrm{tr}}\right)$ following 1 cycle of activation. The MRP group was separated out by subject to properly represent our findings. YNP consisted of $44 \% \pm 3.3 \%$ type 1 muscle fibers and $56 \% \pm 3.3 \%$ type 2 muscle fibers. YCP had $100 \%$ type 2 muscle fibers. MNP had $100 \%$ type 1 muscle fibers. MCP consisted of $14 \% \pm 2.9 \%$ type 1 and $86 \% \pm 2.9 \%$ type 2 muscle fibers. $\mathrm{MRP}_{1}$ and $\mathrm{MRP}_{3}$ had $100 \%$ type 1 muscle fibers, while $\mathrm{MRP}_{2}$ had $100 \%$ type 2 muscle fibers. 


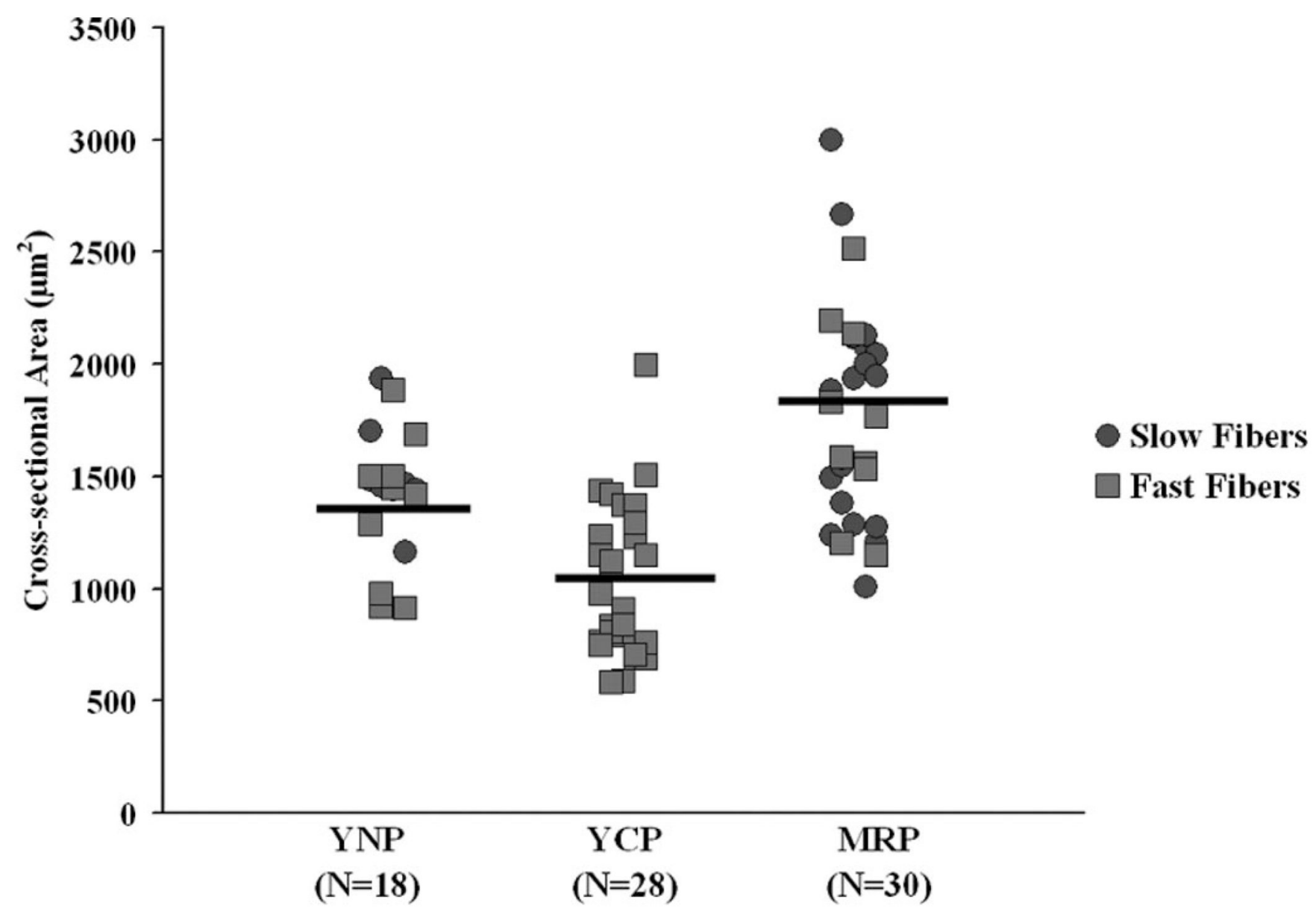

FIGURE 2.

Cross-sectional areas of permeabilized muscle fibers from YNP and YCP and MRP. CSA of MRP group $\left(1780 \pm 74 \mu \mathrm{m}^{2}\right)$ was significantly greater than that of YNP and YCP groups (1286 $\left.\pm 85 \mu \mathrm{m}^{2} ; 1031 \pm 77 \mu \mathrm{m}^{2} ; P=0.0001\right)$. Each black bar represents the average for the corresponding group. Slow and fast fibers are indicated with $\circ$ and $\mathbf{m}$, respectively. 


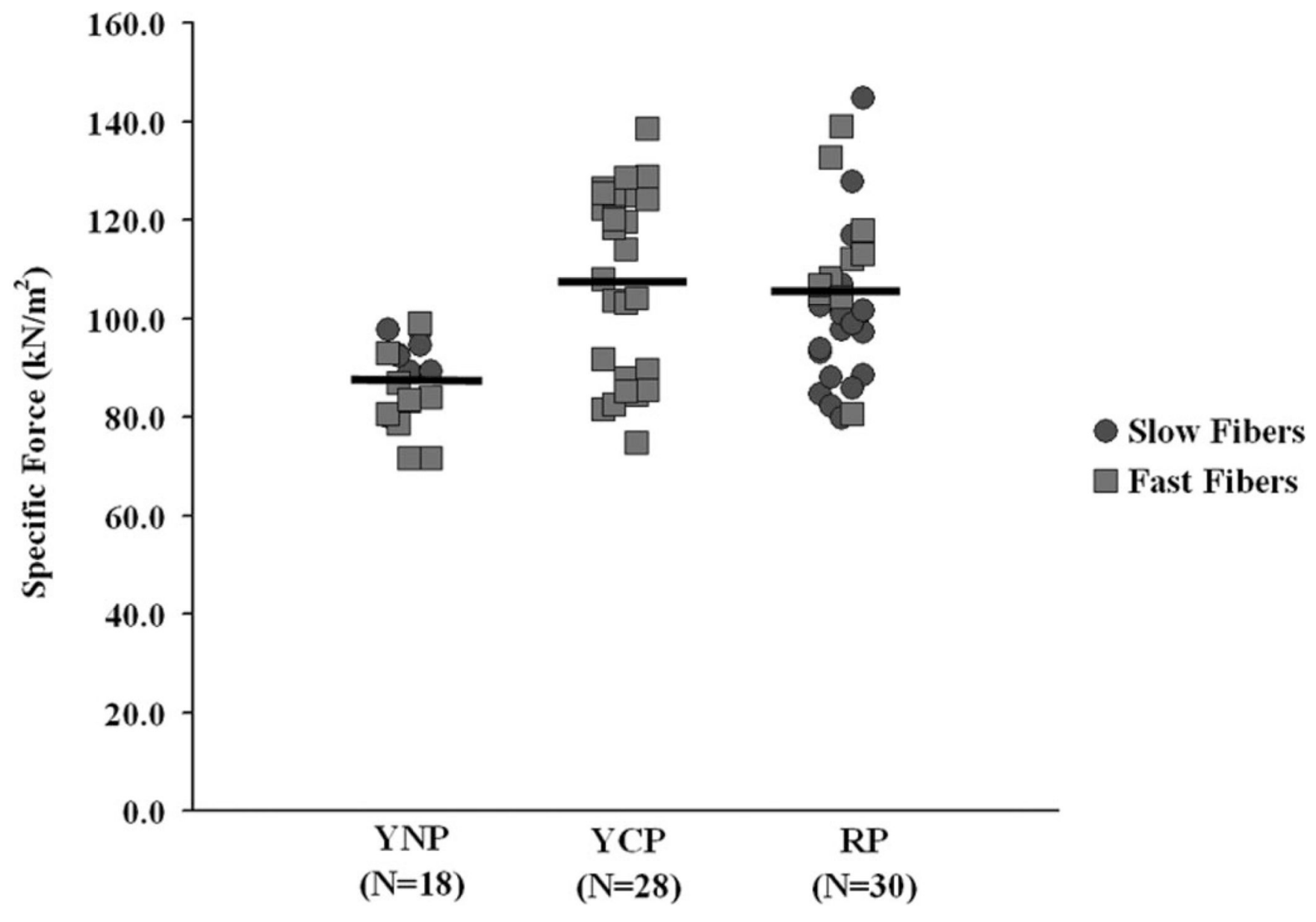

FIGURE 3.

Maximum specific force of YNP and YCP and MRP. YNP muscle fibers produced significantly less $\mathrm{sF}_{0}$ than $\mathrm{YCP}$ and MRP fibers $(P<0.0001 ; P=0.0002)$. The average $\mathrm{sF}_{0}$ of $\mathrm{YNP}$ muscle fibers was $87 \pm 3 \mathrm{kN} / \mathrm{m}^{2}$, YCP was $107 \pm 3 \mathrm{kN} / \mathrm{m}^{2}$, and MRP was $104 \pm 3 \mathrm{kN} / \mathrm{m}^{2}$. Each black bar represents the average for the corresponding group. Slow and fast fibers are indicated with $\circ$ and $\mathbf{m}$, respectively. 


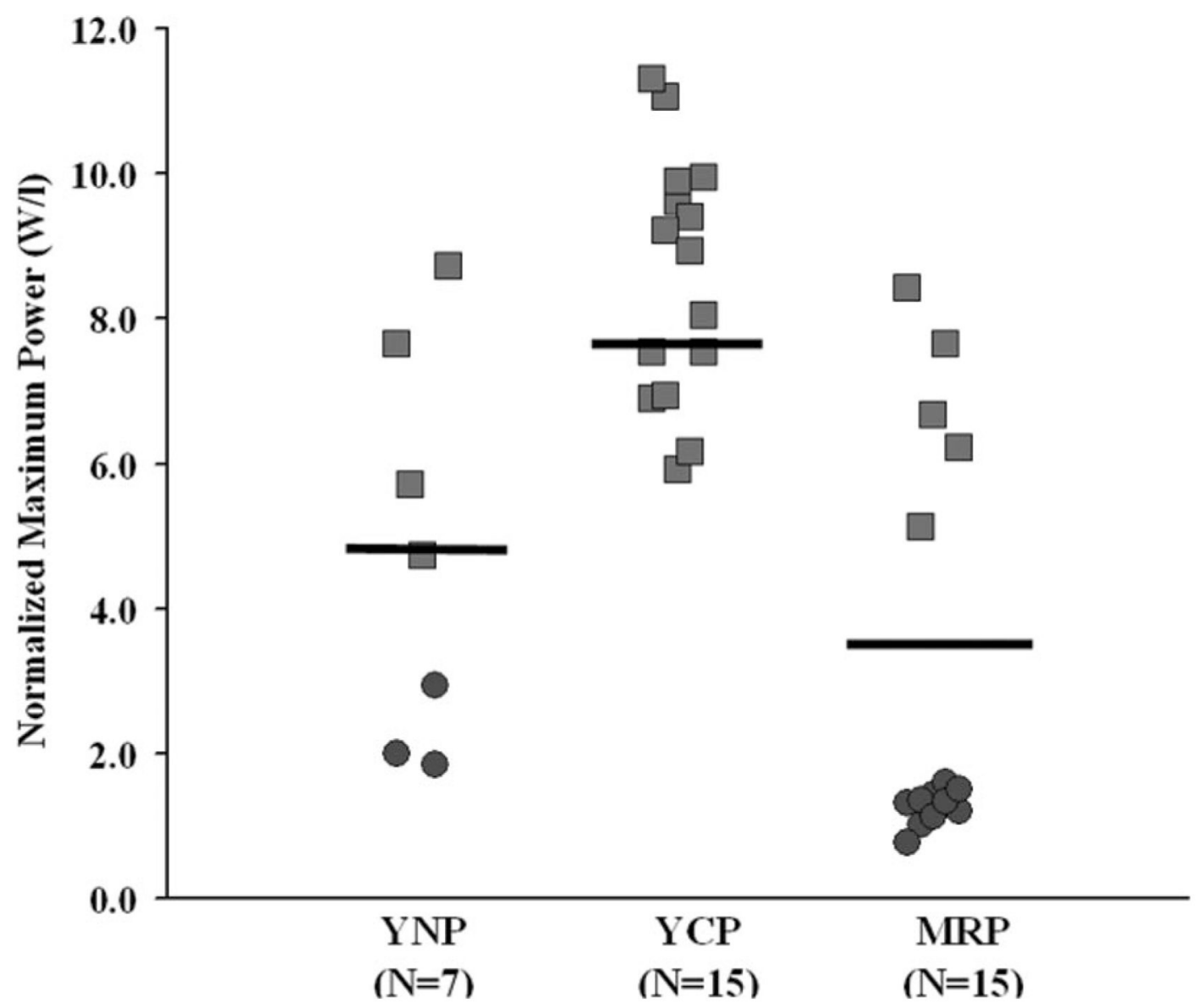

Slow Fibers $\square$ Fast Fibers

FIGURE 4.

Normalize maximum power ( $\left.\mathrm{nP}_{\max }\right)$ of muscle fibers from YNP and YCP and MRP. The average $\mathrm{nP}_{\max }$ of the YCP group $(7.9 \pm 0.5 \mathrm{~W} / \mathrm{l})$ was greater than that of the YNP and MRP groups $(5.1 \pm 0.7 \mathrm{~W} / 1 ; 3.85 \pm 1.9 \mathrm{~W} / 1 ; P=0.0001)$. The average $\mathrm{nP}_{\max }$ of type 1 muscle fibers from YNP $(2.3 \pm 0.2 \mathrm{~W} / \mathrm{l})$ was significantly greater than that of type 1 muscle fibers from MRP $(1.3 \pm 0.1 \mathrm{~W} / 1 ; P=0.0008)$. Type 2 muscle fibers had greater $\mathrm{nP}_{\max }$ values than type 1 muscle fibers within and between all groups (Fig. 4; $P=0.0001$ ). Each black bar represents the average for the corresponding group. Slow and fast fibers are indicated with $\circ$ and $\mathbf{m}$, respectively. 


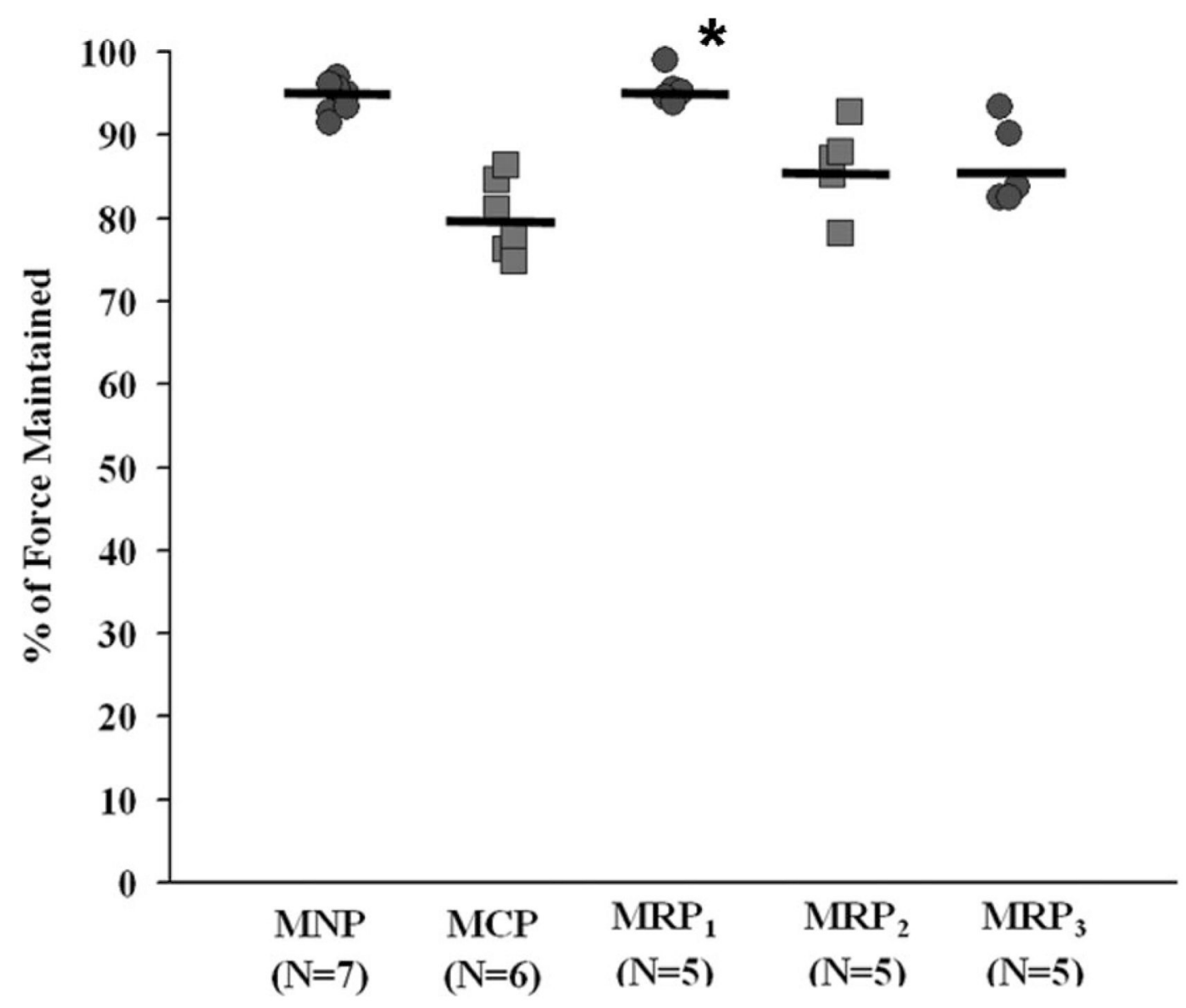

- Slow Fibers

Fast Fibers

FIGURE 5.

Isometric fatigue of muscle fibers from mature normal, mature congenital-cleft palates, and mature repaired palates. $\mathrm{MRP}_{1}$ showed an increased ability to resist fatigue $(96 \% \pm 4 \%)$ compared with the other 2 MRP subjects $(86 \% \pm 3 \% ; 86 \% \pm 2 \% ; P=0.0078)$ and the MCP group $(80 \% \pm 2 \% ; P<0.0001)$. Each black bar represents the average for the corresponding group or subject. Slow and fast fibers are indicated with $\circ$ and $\mathbf{m}$, respectively. 


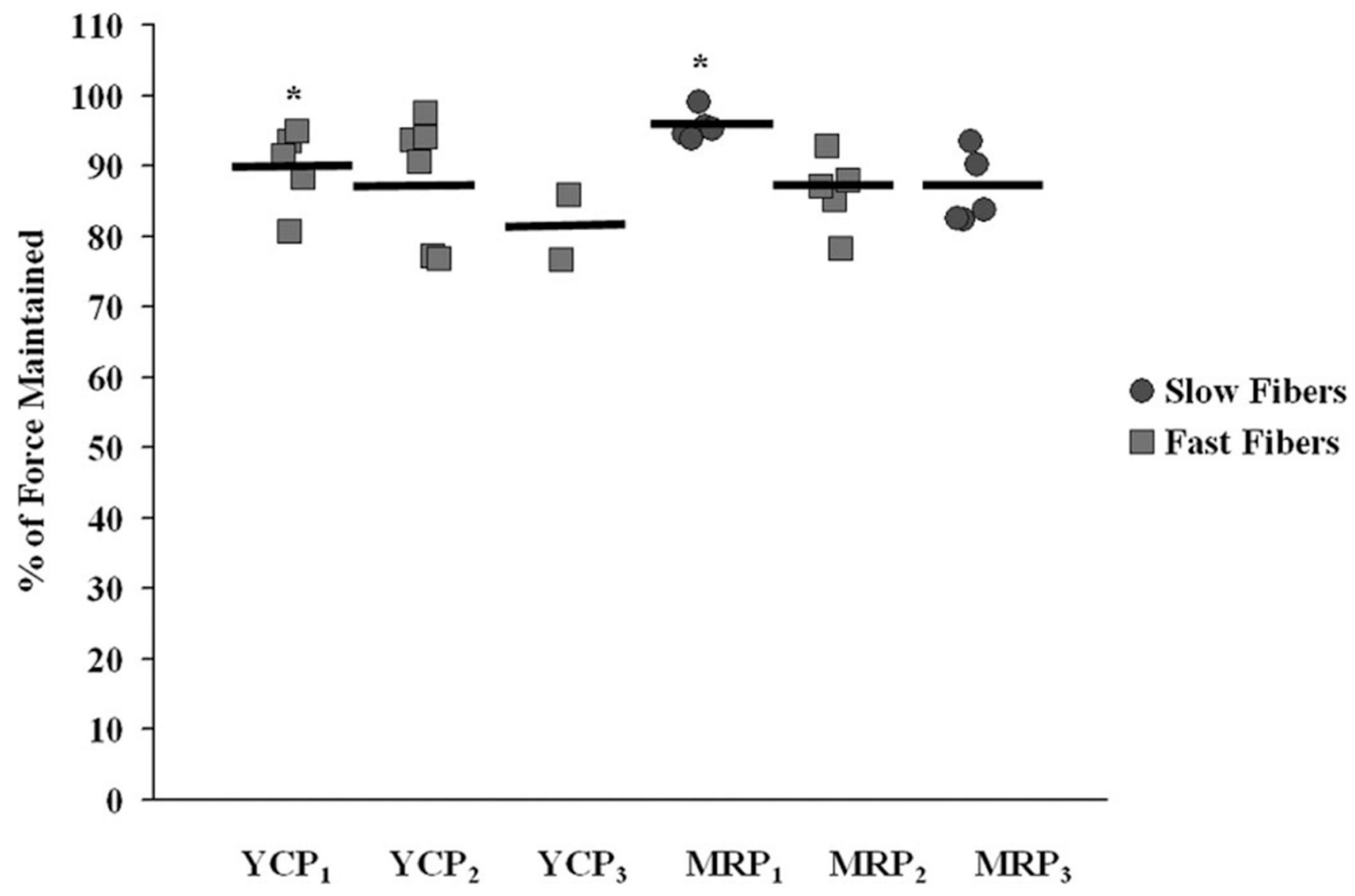

FIGURE 6.

Isometric fatigue of muscle fibers from cleft palates prior to and following repair in the same subjects. Example, $\mathrm{MRP}_{1}=\mathrm{YCP}_{1}$ following repair. $\mathrm{YCP}_{1}$ had a slightly greater, yet not statistically significant $(P=0.1426 ; P=0.7646)$, resistance to fatigue compared with the other $2 \mathrm{YCP}$ subjects. MRP 1 was observed to increase its ability to resist fatigue slightly more, yet not statistically significantly more, than any other subject following palatoplasty compared with the other 2 subjects that underwent palatoplasty. Slow and fast fibers are indicated with $\circ$ and $\mathbf{m}$, respectively. 